Early manuscript of the article: Z. Sebestyén, E. Jakab, Z. May, B. Sipos, K. Réczey Thermal behavior of native, washed and steam exploded lignocellulosic biomass samples Appeared in: Journal of Analytical and Applied Pyrolysis 101 (2013) 61-71

\title{
Thermal behavior of native, washed and steam exploded lignocellulosic biomass samples
}

Zoltán Sebestyén ${ }^{1}$, Emma Jakab ${ }^{1}$, Zoltán May ${ }^{1}$, Bálint Sipos $^{2}$, Kati Réczey ${ }^{2}$

${ }^{1}$ Institute of Materials and Environmental Chemistry, Research Centre for Natural Sciences, Hungarian Academy of Sciences, H-1025 Budapest, Pusztaszeri út 59-67, Hungary

${ }^{2}$ Department of Applied Biotechnology and Food Science, Budapest University of Technology and Economics, H-1111 Budapest, Szent Gellért tér 4, Hungary

Zoltán Sebestyén*:

e-mail: sebestyen.zoltan@ttk.mta.hu

tel: 0036-1-438-1100 extension 580

fax: 0036-1-438-1147

Postal address: Institute of Materials and Environmental Chemistry, Research Centre for Natural Sciences, Hungarian Academy of Sciences, H-1025 Budapest, Pusztaszeri út 59-67, Hungary

Emma Jakab:

jakab.emma@ttk.mta.hu

Zoltán May:

may.zoltan@ttk.mta.hu

Bálint Sipos:

balint_sipos@mkt.bme.hu

Kati Réczey:

kati_reczey@mkt.bme.hu 


\begin{abstract}
The aim of this study was to evaluate the chemical changes in the main components (cellulose, hemicellulose and lignin) of various lignocellulosic biomass samples during the steam explosion pretreatment. Pyrolysis-gas chromatography/mass spectrometry (Py-GC/MS) and thermogravimetry/mass spectrometry (TG/MS) measurements have been performed on different native, washed and steam exploded woody (willow and spruce) and herbaceous (hemp, wheat straw and sweet sorghum bagasse) biomass samples. The main differences between the thermal decomposition of the samples are interpreted in terms of the altered structure of the biomass samples by the effective steam explosion treatment and the different alkali ion contents which have been determined using inductively coupled plasma-optical emission spectroscopy (ICP-OES) method. In order to separate these two effects, the native biomass samples have been washed with hot water to remove the main parts of the potassium and sodium ions. The concentration of $\mathrm{K}^{+}$and $\mathrm{Na}^{+}$has been reduced in the treated biomass samples so the thermal decomposition mechanism has been altered due to the elimination of the catalytic effects. Principal Component Analysis (PCA) has been used to find statistical correlations between the data. The functional group compositions of the lignin molecules have been modified significantly as indicated by the pyrograms and the score plot of the PCA. The amount of hemicellulose has been reduced. On the other hand, the relative amount of the structurally modified cellulose has been increased in the samples by the steam explosion pretreatment step.
\end{abstract}

\title{
Keywords
}

biomass, lignocellulose, steam explosion, pyrolysis, thermogravimetry, principal component analysis

\section{Introduction}

Bioethanol derived from cellulosic biomass is one of the renewable alternatives to fossil fuels [1-3] which has the potential to reduce the environmental effects of the transportation and the dependence on the depleting fossil reserves. Plants with high cellulose content can be used as raw materials in the second generation bioethanol process [2-5] to produce the ethanol ecologically more competitive in comparison with the starch- and sugar-based ethanol production [6].

The three main components of the lignocellulosic raw materials are cellulose, hemicellulose and lignin. Cellulose can be converted to its building monomer - glucose - by cellulase enzyme complex [2-5]. The main function of hemicellulose and lignin is to make the cell wall more consistent and to protect cellulose fibrils against the attack of the cellulose degrading microorganisms. Hemicellulose is a branched heteropolysaccharide containing both pentose (xylose, arabinose) and hexose (mannose, galactose, glucose) monomers [7, 8]. Lignin is a cross-linked polymer containing mainly hydroxyphenylpropanol monomers methoxylated to different degree and coupled with $\beta-4-\mathrm{O}$ bonds. The structures of lignins are different in various species of plants [7, 9-12]. Prior to the enzymatic hydrolysis, pretreatment of the raw materials by physical and chemical methods is necessary to break the complex lignocellulosic fibers, reduce the crystallinity and raise the digestibility of the cellulose [10, 13-15]. Pretreatment methods can be divided into different categories. Group of physical methods 
contains for example hydrothermolysis, grinding, and milling [13, 16, 17]. Pretreatment by diluted acid, alkaline or ammonia solutions makes different chemical changes in the structure of the lignocellulosic biomass [18, 19]. Haverty et al. [20] used the autocatalytic decomposition by $\mathrm{H}_{2} \mathrm{O}_{2}$ and formic acid pretreatment for the fractionation of the cellulasedigestible part of the biomass material from the hemicellulose and lignin fraction. Biological methods are often combined with other, more powerful pretreatment steps [5, 21].

Steam explosion is recognized as one of the most cost-effective pretreatment process [22, 23] with high effectiveness especially for softwoods [24, 25]. During this method biomass is treated with high-pressure saturated steam and then the pressure is suddenly reduced, which makes the materials undergo an explosive decompression. The applied temperature and pressure of the steam explosion can influence the effectiveness of the pretreatment process $[26,27]$. The three main effects of the steam explosion are the hydrolysis of the hemicellulose fraction, changing the structure of lignin components and reducing the alkali ion content of the samples [23-25]. This pretreatment method can become more effective with the addition of sulfuric acid or sulfur dioxide catalysts. The duration, temperature and formation of inhibitors before the enzymatic steps can be decreased by the addition of impregnation materials during the steam explosion [28, 29].

Thermoanalytical and pyrolysis methods are useful to determine differences between the structures of biomass samples without separating the main fractions [9, 19, 30, 31]. In this study thermogravimetry/mass spectrometry (TG/MS) and pyrolysis-gas chromatography/mass spectrometry (Py-GC/MS) measurements have been carried out to study the differences in the thermal decomposition of the native, hot water washed and steam exploded lignocellulosic raw materials. The evolutions of decomposition products as well as the thermal stability of the treated and untreated samples were measured by TG/MS. The changes in the structure of the lignin components of woody and herbaceous samples were examined by the method of PyGC/MS. The inorganic ion contents of the biomass samples were analyzed by ICP-OES system. The effects of the different alkali ion contents and steam explosion have been studied on the thermal behavior of woody and herbaceous samples with the goal to find statistical correlations between the thermal behavior, the effect of steam explosion pretreatment and the reduced alkali ion content of the samples.

\section{Experimental}

\section{Materials}

Untreated, washed and steam exploded biomass samples were measured by thermoanalytical methods. The native and pretreated biomass samples were ground by a cutting mill to $<1 \mathrm{~mm}$ and further ground to $<0.12 \mathrm{~mm}$ particle size by a rotor mill. A part of ground native woody and herbaceous samples was washed with $60^{\circ} \mathrm{C}$ hot water for 2 hours. After the washing the filtered and wet, raw materials were dried at $105^{\circ} \mathrm{C}$. The experimental conditions of the steam explosion pretreatments are given in Table 1 . The pretreatment conditions have been selected based on optimization for increased enzymatic degradability (highest glucose conversion in enzymatic hydrolysis) for each biomass in earlier studies [4, 32-35]. The 
severity factor $\left(\mathrm{R}_{0}\right)$, introduced by Overend and Chornet [36], is given in Table 1 for each steam exploded sample.

Table 1

The experimental conditions of the steam explosion pretreatment.

\begin{tabular}{lccccc}
\hline Sample & $\begin{array}{c}\text { Temperature } \\
/{ }^{\circ} \mathrm{C}\end{array}$ & $\begin{array}{c}\text { Duration } \\
/ \text { min }\end{array}$ & $\begin{array}{c}\text { Impregnation } \\
\text { material }\end{array}$ & $\log \mathrm{R}_{0} *$ & Reference \\
\hline Willow & 190 & 12 & $2 \% \mathrm{SO}_{2}$ & 3.73 & P. Sassner et al. [32] \\
Spruce & 210 & 5 & $2.5 \% \mathrm{SO}_{2}$ & 3.94 & K. Stenberg et al. [33] \\
Hemp & 205 & 5 & $2 \% \mathrm{SO}_{2}$ & 3.79 & B. Sipos et al. [4] \\
Wheat straw & 190 & 10 & $0.2 \% \mathrm{H}_{2} \mathrm{SO}_{4}$ & 3.65 & M. Linde et al. [34] \\
$\begin{array}{l}\text { Sweet sorghum } \\
\text { bagasse }\end{array}$ & 190 & 10 & $2 \% \mathrm{SO}_{2}$ & 3.65 & B. Sipos et al. [35] \\
\hline
\end{tabular}

*Pretreatment severity factor: $\log R_{0}=\log \left[t \cdot\left(\exp \frac{T-100}{14.75}\right)\right]$ where $t$ means time in minute and

$T$ means temperature in degrees centigrade.

\section{Methods}

Pyrolysis-GC/MS

Approximately $0.8 \mathrm{mg}$ samples were pyrolyzed at $600{ }^{\circ} \mathrm{C}$ for $20 \mathrm{~s}$ in helium atmosphere using a Pyroprobe 2000 pyrolyzer interfaced to an Agilent 6890A/5973 GC/MS. The pyrolysis products were separated on a DB-1701 capillary column $(30 \mathrm{~m} \times 0.25 \mathrm{~mm}, 0.25 \mu \mathrm{m}$ film thickness). The GC oven was programmed to hold at $40^{\circ} \mathrm{C}$ for $2 \mathrm{~min}$ then increase the temperature to $280{ }^{\circ} \mathrm{C}$ (hold for $5 \mathrm{~min}$ ) at a rate of $6{ }^{\circ} \mathrm{C} \mathrm{min}^{-1}$. The mass range of $\mathrm{m} / \mathrm{z}, 14-500$ was scanned by the mass spectrometer in electron impact mode at $70 \mathrm{eV}$.

\section{$T G / M S$}

The TG/MS system consists of a modified Perkin-Elmer TGS-2 termobalance and a Hiden HAL quadrupole mass spectrometer. About $3 \mathrm{mg}$ samples were measured in argon atmosphere at a flow rate of $140 \mathrm{ml} \mathrm{min}{ }^{-1}$. The samples were heated at a rate of $20{ }^{\circ} \mathrm{C} \mathrm{min}{ }^{-1}$ from 25 to $950{ }^{\circ} \mathrm{C}$ in a platinum sample pan. The evolved products were introduced through a glass lined metal capillary heated at $300{ }^{\circ} \mathrm{C}$ into the ion source of the mass spectrometer which was operated at $70 \mathrm{eV}$ electron energy.

\section{ICP-OES}

About $2 \mathrm{~g}$ samples were ashed at $550{ }^{\circ} \mathrm{C}$ in a furnace. Ashes were fused at $920^{\circ} \mathrm{C}$ with a fusion blend $\left(\mathrm{Li}_{2} \mathrm{~B}_{4} \mathrm{O}_{7}: \mathrm{LiBO}_{2}, 2: 1\right)$ and digested by $25 \mathrm{~cm}^{3} 33 \%$ nitric acid. Potassium, sodium and sulfur contents of the samples were determined by a Spectro Genesis ICP-OES equipment (Spectro Analytical Instruments) with axial plasma observation. The amounts of the ashes have been determined using CEN/TS 14775 EU standard method. 


\section{Results and discussions}

\section{Characterization of the samples}

The steam explosion reduces the potassium and sodium ion contents of the samples, which is well-known to influence the thermal decomposition mechanism of cellulose and lignin [19, 37-43]. To distinguish between the catalytic effect of the different alkali ion contents and the structural changes due to the steam explosion, we prepared hot water washed samples for comparison since hot water washing for 2 hours removes the majority of the alkali ions [44, 45]. Table 2 shows the yields of volatiles and carbonaceous residues (chars) at $850{ }^{\circ} \mathrm{C}$, the ash, sodium and potassium ion contents as well as the sulfur content of the untreated, washed and steam exploded biomass samples. In each case the yield of volatiles increased and the amount of char and ash decreased due to the washing. A considerable part of the alkali ion contents of the samples was dissolved by the hot water so the decomposition mechanism of the lignocelluloses was changed. Depolymerization is the preferred decomposition route in the washed samples at the expense of the fragmentation and char formation [19, 46-48]. The potassium and sodium ion contents of the samples were decreased due to the steam explosion as well. Native woody samples contain much less $\mathrm{K}^{+}$and $\mathrm{Na}^{+}$than the herbaceous biomass samples. In all cases the sodium ions were dissolved by the $60{ }^{\circ} \mathrm{C}$ water more effectively than by the steam explosion, just like the potassium ions in the cases of willow and spruce samples. About $90 \%$ of the potassium and $80 \%$ of the sodium ion content were extracted by the hot water and more than $70 \%$ of the potassium and $40 \%$ of the sodium ion contents were removed by the steam explosion pretreatment. This could be more effective using more washing steps after the pretreatment. Although the potassium and sodium ion contents decreased significantly, the ash contents did not reduce proportionally or even increased in a few steam exploded samples. Apparently, sulfonate groups were introduced into the samples from the $\mathrm{SO}_{2}$ catalyst of the steam explosion. After the $\mathrm{SO}_{2}$ catalyzed pretreatment step, the sulfur content of willow and spruce increased 3-4 times in comparison with the native samples (Table 2). The sulfur concentration of hemp and sweet sorghum bagasse is increased after the steam explosion but to a lower degree comparing to the woody samples. The formation of $\mathrm{SO}_{2}$ during pyrolysis demonstrates the higher concentration of sulfur in the steam exploded hemp sample (Fig. 5 and Table 3). It is interesting to note that the sulfur content of wheat straw decreased by a factor of 4 during the steam explosion pretreatment, where $\mathrm{H}_{2} \mathrm{SO}_{4}$ was used as an impregnation material. Similar effect was observed after the hot water washing: the washed biomass samples contain negligible amount of sulfur. It is likely that the sulfate groups can be removed by dilute acid or hot water washing. 
Table 2

Characterization of the measured biomass samples on dry basis.

\begin{tabular}{|c|c|c|c|c|c|c|c|}
\hline Sample & Treatment & $\begin{array}{c}\text { Volatiles } \\
(\%)\end{array}$ & $\begin{array}{l}\text { Char } \\
(\%)\end{array}$ & $\begin{array}{l}\text { Ash } \\
(\%)\end{array}$ & $\begin{array}{c}\mathrm{K}^{+} \text {content } \\
(\mathrm{ppm})\end{array}$ & $\begin{array}{l}\mathrm{Na}^{+} \text {content } \\
(\mathrm{ppm})\end{array}$ & $\begin{array}{c}\text { S content } \\
(\mathrm{ppm})\end{array}$ \\
\hline \multirow{3}{*}{ Willow } & - & 84.1 & 15.9 & 1.11 & 2479 & 359 & 100 \\
\hline & Washing & 87.3 & 12.7 & 0.59 & 38 & 56 & 24 \\
\hline & Steam explosion & 81.3 & 18.7 & 1.14 & 729 & 220 & 374 \\
\hline \multirow{3}{*}{ Spruce } & - & 85.4 & 14.6 & 0.32 & 747 & 305 & 48 \\
\hline & Washing & 86.9 & 13.1 & 0.11 & 15 & 22 & 6 \\
\hline & Steam explosion & 76.2 & 23.8 & 0.16 & 203 & 141 & 132 \\
\hline \multirow{3}{*}{ Hemp } & - & 80.5 & 19.5 & 2.83 & 12954 & 1014 & 281 \\
\hline & Washing & 86.8 & 13.2 & 0.91 & 1170 & 67 & 44 \\
\hline & Steam explosion & 87.2 & 12.8 & 0.83 & 610 & 185 & 399 \\
\hline \multirow{3}{*}{$\begin{array}{l}\text { Wheat } \\
\text { straw }\end{array}$} & - & 75.7 & 24.3 & 6.28 & 15862 & 1724 & 400 \\
\hline & Washing & 82.8 & 17.2 & 5.02 & 1036 & 289 & 61 \\
\hline & Steam explosion & 82.5 & 17.5 & 5.08 & 79 & 731 & 101 \\
\hline \multirow{3}{*}{$\begin{array}{c}\text { Sweet } \\
\text { sorghum } \\
\text { bagasse }\end{array}$} & - & 78.6 & 21.4 & 3.74 & 14122 & 968 & 167 \\
\hline & Washing & 85.9 & 14.1 & 2.67 & 1333 & 173 & 21 \\
\hline & Steam explosion & 83.6 & 16.4 & 4.16 & 2568 & 599 & 172 \\
\hline
\end{tabular}

\section{TG-MS results}

In Fig. 1, the thermogravimetry (TG) and derivative thermogravimetry (DTG) curves of the woody samples are presented. The char yield of the biomass samples is greatly influenced by two factors: the lignin content and the alkali ion content. The lignin produces about $30 \%$ char $[9,42]$, while cellulose yields only about $5 \%[46,48]$ and hemicellulose has about 5-10 \% residue. The alkali ion content has a catalytic effect on the charring reactions: the higher the alkali ion content of the biomass the higher the char yield and the gas evolution during thermal decomposition [19]. The amounts of the carbonaceous residue of washed samples (Fig. 1a and c) are lower than that of the native samples because greater part of the alkali ion content was dissolved by the hot water washing (data are given in Table 2). Depolymerization is the main mechanism during the thermal decomposition of cellulose, therefore lower char yield is generated in the washed samples [19, 37, 47, 48]. Although most of the potassium and sodium ions were eliminated by the expanded hot steam during the steam explosion pretreatment, more char was formed during the thermogravimetry measurement. This observation can be explained by changes in the composition of wood samples during steam explosion: the relative amount of lignin molecules was increased due to the significant decrease of the hemicellulose fraction.

Fig. 1b (willow) and d (spruce) shows significant changes in the decomposition mechanism caused by the washing and the steam explosion. The main DTG peak can be attributed to the thermal degradation of cellulose. Values of the maximum rate of the thermal decomposition $\left(\mathrm{DTG}_{\max }\right.$ ) of the native samples are $0.299 \% \mathrm{~s}^{-1}$ at $381^{\circ} \mathrm{C}$ (willow) and $0.347 \% \mathrm{~s}^{-1}$ at $391^{\circ} \mathrm{C}$ 
(spruce). After the washing the decomposition shifts to a slightly higher temperature range with a higher value of $\mathrm{DTG}_{\max }$ (willow: $0.339 \% \mathrm{~s}^{-1}$ at $391^{\circ} \mathrm{C}$; spruce: $0.407 \% \mathrm{~s}^{-1}$ at $397^{\circ} \mathrm{C}$ ). The shoulder on the DTG peak can be attributed to the decomposition of hemicellulose which is separated much better after the washing with hot water. The majority of the hemicellulose fraction was removed during the steam explosion so the relative amount of the modified lignin and cellulose fraction increased in the composition of samples. The maximum rate of the thermal decomposition is at about $330{ }^{\circ} \mathrm{C}\left(\mathrm{T}_{\text {peak }}\right)$ in case of steam exploded woody samples. Intra- and intermolecular hydrogen bonds broke up during the steam explosion [25] and the crystallinity of the cellulose molecules decreased during the pretreatment. The cellulose molecules were probably fragmented, too. Due to these changes in the structure of cellulose, the $\mathrm{T}_{\text {peak }}$ and the corresponding value of the $\mathrm{DTG}_{\max }$ decreased in the thermogravimetric experiment. The thermal decomposition of the steam exploded willow and spruce ends above $500{ }^{\circ} \mathrm{C}$. The shoulder at about $420{ }^{\circ} \mathrm{C}$ on the DTG curves of the steam pretreated samples can be attributed to the relatively increased amount of lignin.
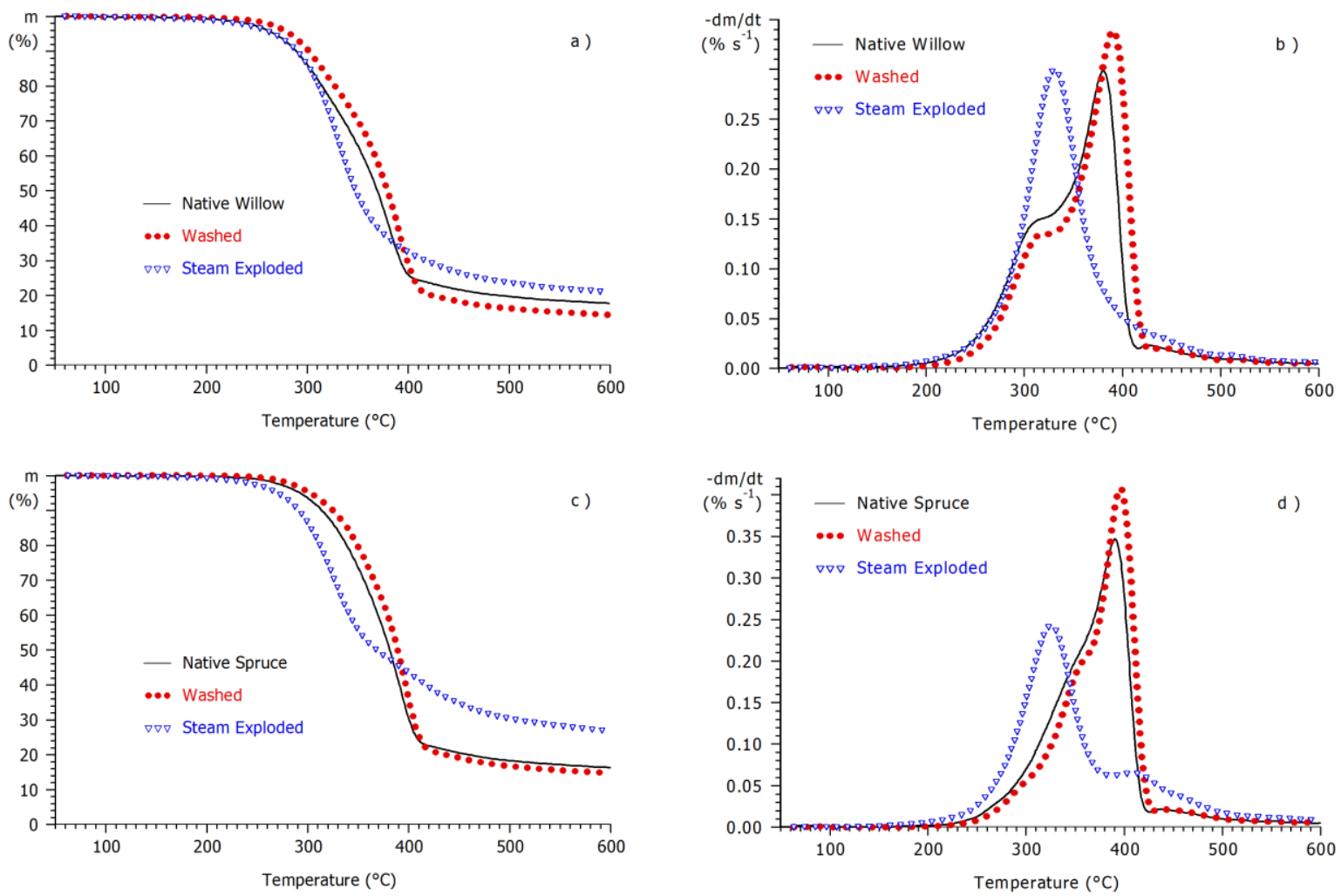

Fig. 1. (a, c) TG and (b, d) DTG curves of native and treated woody samples.

Fig. 2 shows the TG and DTG curves of native, washed and steam exploded herbaceous samples. The char yield of the herbaceous samples is much higher than that of woody samples due to the high mineral matter content and the catalytic effect of the high alkali content (Table 2). The yield of carbonaceous residue decreased in case of washed as well as steam exploded samples because a great part of the alkali ion content was removed by the washing or steam explosion (Table 2). The DTG curves of the samples illustrate the effect of the washing and the steam explosion on the thermal decomposition. Owing to the decreased potassium and sodium ion content, the thermal decomposition of washed and pretreated samples starts at 
higher temperature and has a higher maximum of decomposition rate $\left(\mathrm{DTG}_{\max }\right)$ at a higher temperature $\left(\mathrm{T}_{\text {peak }}\right)$ compared to the untreated samples. On the DTG curves of the native samples the main peak - attributed mainly to the thermal decomposition of cellulose - covers the characteristic shoulder generated by the degradation of hemicellulose fraction. This shoulder can be clearly seen on the DTG curves of the washed samples because the thermal degradation of cellulose shifted to a higher temperature range due to the strongly reduced $\mathrm{K}^{+}$ and $\mathrm{Na}^{+}$contents. The cellulose decomposes at the same temperature range in the steam exploded samples but the characteristic shoulder is missing because the hemicellulose fraction was strongly decreased by the steam explosion pretreatment.
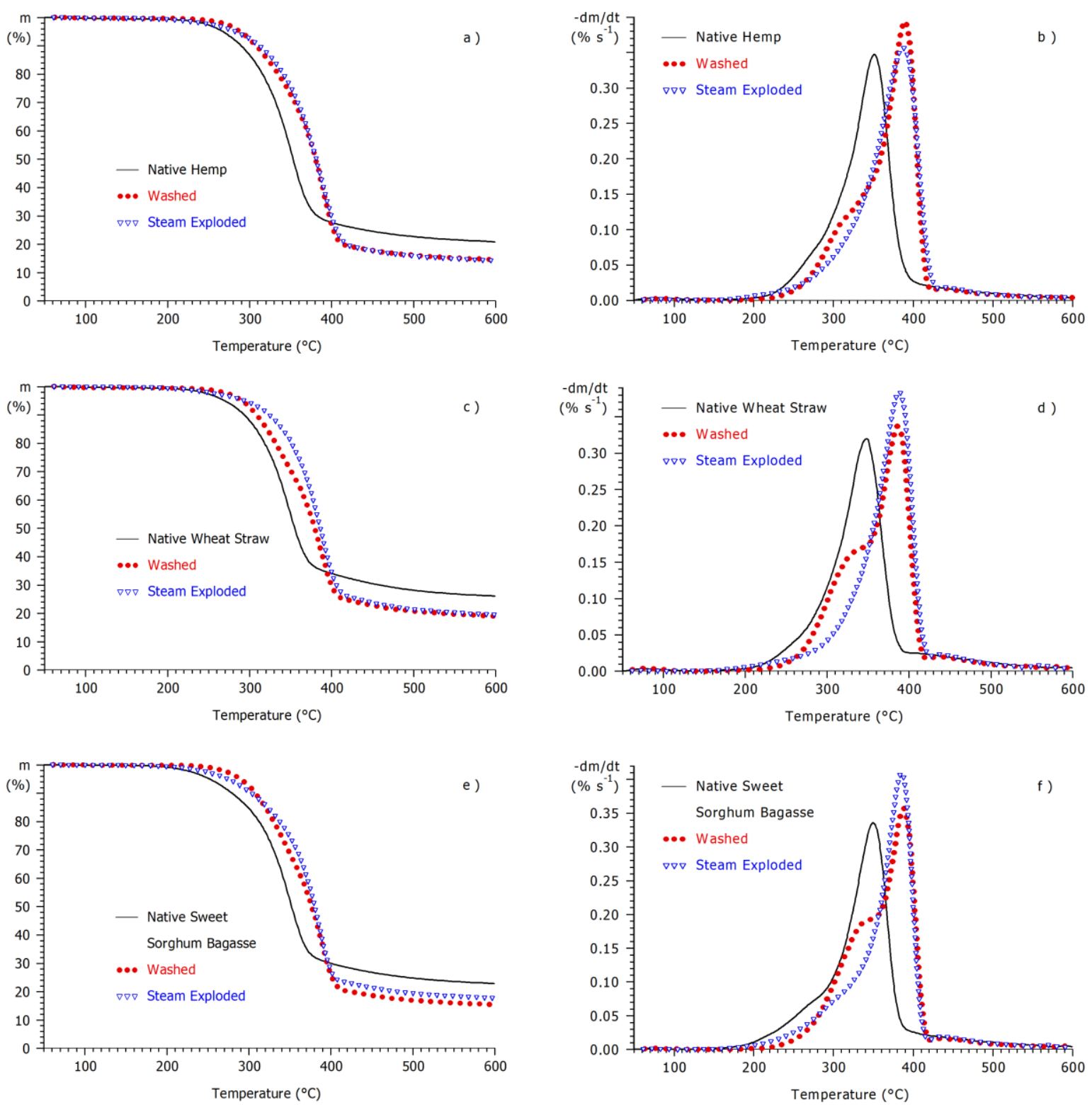

Fig. 2. (a, c, e) TG and (b, d, f) DTG curves of the herbaceous samples. 
Fig. 3 illustrates the DTG curves as well as the evolution profiles of a few important decomposition products of native, washed and steam exploded spruce. The fragment ion $\mathrm{m} / \mathrm{z}$ 95 and the molecular ion $\mathrm{m} / \mathrm{z}, 96$ can be attributed to furfural formed from both hemicellulose and cellulose. Relatively high yield of water $(\mathrm{m} / \mathrm{z}, 18)$ is produced during the thermal decomposition of wood due to the large number of hydroxyl groups present in carbohydrates and lignin. It is likely that the $\mathrm{m} / \mathrm{z}, 30$ ion represents mainly formaldehyde during the TG/MS experiment. Fragment ions of other molecules can attribute to the intensity of $\mathrm{m} / \mathrm{z} 30$ ions to a smaller degree since the high molecular mass products can not be analyzed by this method. Formaldehyde $(\mathrm{m} / \mathrm{z} 30)$ also represents a general product of hemicellulose, cellulose and lignin. Fragment ion $\mathrm{m} / z 31$ originates mainly from the methanol evolution during the thermal decomposition. On the other hand this fragment can be formed from various decomposition products e.g., hydroxyacetaldehyde, which is released from cellulose. The methane formation is monitored by its molecule ion $(\mathrm{m} / \mathrm{z}, 16)$. The mass spectrometric curve $\mathrm{m} / \mathrm{z} 16$ can only be attributed to methane because the $\mathrm{m} / \mathrm{z} 16$ fragment ions of water, carbon monoxide and carbon dioxide were subtracted by the analyzing program. The evolution of the $\mathrm{m} / \mathrm{z} 15$ methyl ion fragments is parallel with the formation of the molecule ions $\mathrm{m} / \mathrm{z} 16$ in the temperature range $350-750{ }^{\circ} \mathrm{C}$. Methane can be formed during two main reactions. The first methane peak (from 350 to $470{ }^{\circ} \mathrm{C}$ ) on the mass spectrometric curve of native spruce sample (Fig. 3a) can be attributed to the thermal decomposition of lignin fraction $[9,19,42]$. The slow charring processes start at about $470{ }^{\circ} \mathrm{C}$ and last till about $750{ }^{\circ} \mathrm{C}$ with the release of methane. These two stages can be observed on the mass spectrometric curve of methane during the thermal decomposition of washed spruce sample as well (Fig. 3b). During the thermal degradation of steam exploded spruce (Fig. 3c) the enhanced methane evolution between $370^{\circ} \mathrm{C}$ and $510^{\circ} \mathrm{C}$ reflects the increased ratio of lignin in the steam exploded spruce sample.

The shoulder on the DTG curves at about $340{ }^{\circ} \mathrm{C}$, characterized by mass spectrometric peaks of e.g. methanol, formaldehyde, furfural and water (Fig. 3a and b), demonstrates the presence of hemicellulose in the native and washed samples. This shoulder disappears during the thermal decomposition of steam exploded samples due to the strongly reduced hemicellulose content (Fig. 3c). The evolution of water, formaldehyde and furfural shows that the thermal degradation of cellulose shifted to lower temperature (from $200{ }^{\circ} \mathrm{C}$ to $400{ }^{\circ} \mathrm{C}$ ) in the steam exploded spruce sample indicating a reduction in the molecular mass or a change in the crystalline structure of cellulose during the treatment (Fig. 3c). This sample was treated under the severest conditions: at $210{ }^{\circ} \mathrm{C}$ with $2.5 \% \mathrm{SO}_{2}$ catalyst. 

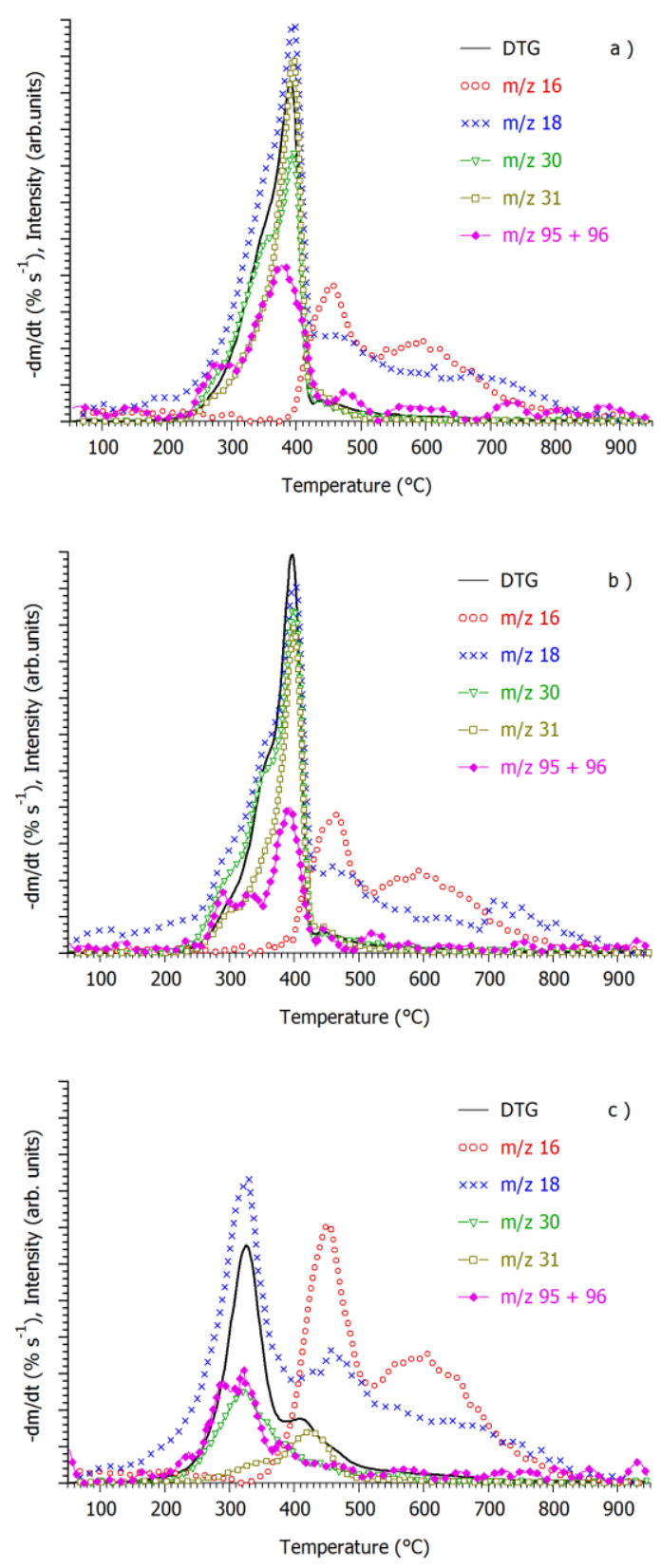

Fig. 3. DTG and mass spectrometric curves of (a) native, (b) washed and (c) steam exploded spruce.

The herbaceous samples behave slightly differently as illustrated by the TG/MS curves of wheat straw in Fig. 4. Due to the higher alkali content, the native sample decomposes at lower temperature because the cellulose decomposition is shifted to lower temperature and is not separated from the decomposition of hemicellulose (Fig. 4a). After the hot water washing, the hemicellulose presents a shoulder on the DTG curve at about $330{ }^{\circ} \mathrm{C}$ (Fig. 4b). This fact is supported by the mass spectrometric curves as shown by the curves of the wheat straw samples in Fig. 4. The thermal decomposition of cellulose and hemicellulose can be characterized by the mass spectrometric ion $m / z 60$. The peak at about $380{ }^{\circ} \mathrm{C}$ can be attributed to hydroxyacetaldehyde formed by the thermal decomposition of cellulose and the characteristic shoulder on the evolution curve of $\mathrm{m} / \mathrm{z} 60$ can represents acetic acid evolving 
from the hemicellulose. The assignment is confirmed by the fragment ions of these molecules (not shown here). The main evolution temperature of the decomposition products from steam exploded wheat straw sample (Fig. 4c) is between 300 and $430{ }^{\circ} \mathrm{C}$, so the cellulose decomposition does not shift to lower temperature as during the decomposition of steam exploded wood samples. Apparently the cellulose fraction of herbaceous samples does not suffer so drastic depolymerization as that of the woody samples due to the less severe conditions during the steam explosion. The enhanced methane formation $(\mathrm{m} / \mathrm{z}, 16)$ from the lignin component at about $450{ }^{\circ} \mathrm{C}$ indicates the increased relative amount of lignin in the steam exploded sample similarly to woody samples.


Fig. 4. DTG and mass spectrometric curves of (a) native, (b) washed and (c) steam exploded wheat straw. 


\section{Pyrolysis results}

Pyrolysis-gas chromatography/mass spectrometry has been applied to reveal the changes in the pyrolysis product distribution of the samples after washing and steam explosion. The pyrolysis temperature was chosen $600{ }^{\circ} \mathrm{C}$ because the TG/MS results showed that the thermal decomposition of the woody and herbaceous samples ended below this temperature. Fig. 5 shows the volatile products originating from native (a), washed (b) and steam exploded (c) hemp samples as examples for the pyrograms of the herbaceous samples. The numbering and identification as well as the relative intensities of the pyrolysis products are listed in Table 3. The identification of the products is based on NIST mass spectral library and literature data [49-54]. The mass spectra of carbohydrate derivatives are very similar, so the relative retention times of the individual compounds given by Faix et al. [51] were also used for the identification. The peaks at lower retention times $(\mathbf{e . g . ,} \mathbf{2}, \mathbf{4}, \mathbf{6 , 9})$ correspond to the main smaller molecular mass products of cellulose and hemicellulose. The yield of these molecules reduced after washing and even stronger decreased after steam explosion. The presence of alkali ions in the native hemp sample enhances the char formation and the fragmentation leading to the release of small molecules. The greater part of alkali ions was removed by the hot water washing as well as by the steam explosion, so the decomposition mechanism was changed in the treated samples. Characteristic thermal decomposition product of cellulose component is hydroxy-acetaldehyde (7), which is increased from the washed hemp and reduced from the steam exploded sample. The main decomposition product of cellulose under inert atmosphere is levoglucosan (39) [46], a dehydrated derivative of glucose. The relative amount of the released levoglucosan is about $8 \%$ from the native hemp sample calculating the area $\%$ values of the volatile products. This value is almost 4 times higher (29\%) from the washed hemp and 9 times higher ( $75 \%$ ) from the steam exploded sample (Table 3 ). As discussed above, the removal of alkali ions by the hot water washing and steam explosion altered the decomposition mechanism and enhanced the depolymerization reactions leading to levoglucosan formation [19, 46-48]. The higher cellulose content also contributes to the significantly higher levoglucosan yield from the steam exploded sample caused by the removal of the majority of the hemicellulose component during the treatment. Higher yield of other carbohydrate products is observed from the treated hemp samples, like pyranone (32) and glucofuranose derivative (46). The latter molecule is not formed in case of native and washed samples (Fig. 5a and b).

Acetic acid (8), 3-hydroxypropanal (10) and 4-hydroxy-5,6-dihydro-(2H)-pyran-2-one (16) are the most typical decomposition products of hemicellulose component under inert atmosphere. The yields of these molecules significantly decreased from the steam exploded sample that indicates the reduction of the hemicellulose component during the steam explosion in agreement with the literature data [4, 24-28]. This finding has been confirmed by the TG/MS curves of the samples (Fig. 3 and 4) as well. Furfural (13) originates from both cellulose and hemicellulose; its intensity is also significantly diminished from the steam exploded sample due to the decreased hemicellulose component. However, small amount of hemicellulose remained in the steam exploded sample which is indicated by the evolution of 
an anhydro-xylofuranose (34) and anhydro-galactopyranose (37) that are probably formed from xylan and galactan, respectively.

Hemp lignin belongs to HGS-type lignins; the abbreviation $\mathrm{H}, \mathrm{G}, \mathrm{S}$ refers to the presence of 4-hydroxyphenylpropanol, guaiacylpropanol and syringylpropanol units in the lignin macromolecules. Phenol (18), guaiacol and its derivatives $(\mathbf{1 9}, \mathbf{2 1}, \mathbf{2 3}, \mathbf{2 7}, \mathbf{3 3}, \mathbf{4 3}, \mathbf{4 4})$ as well as syringol and its derivatives $(\mathbf{3 0}, \mathbf{3 5}, \mathbf{3 6}, \mathbf{4 0}, \mathbf{4 1}, \mathbf{4 5}, \mathbf{4 7 - 5 0})$ are the major products of HGS lignins as it can be seen in the pyrograms after the retention time of $16.9 \mathrm{~min}$ in Fig. 5. Steam explosion changed the structure of lignin macromolecules as indicated by the altered intensity of several monomeric lignin products during pyrolysis. The oxidation effect of the steam explosion is shown by the evolution of $\alpha$-oxy-lignin product (38) from the steam pretreated sample. Another effect of steam explosion is the cleavage of methoxy groups from the lignin molecules as shown in Scheme 1. This observation is supported by the reduction of syringol derivatives (Table 3) and increasing of lignin monomeric products without methoxy groups in the pyrograms. Table 4 presents the enhanced formation of 3-methoxycatechol and catechol during pyrolysis. In case of herbaceous samples and hardwood (willow), the methoxy group of the syringol moieties loses a methyl group under the steam explosion, for example, 3methoxycatechol (26) unit is formed from the syringol moieties. There are no syringol molecules in the lignin component of spruce, so the yield of guaiacol decomposition products is reduced. The guaiacol units of the spruce lignin suffer a demethylation reaction as well resulting in enhanced catechol release during pyrolysis. Further changes in the structure of lignin molecules are shown by the peak intensities of trans-coniferyl alcohol (43), coniferyl aldehyde (44), synapyl alcohol $(\mathbf{4 8}, \mathbf{4 9})$ and synapaldehyde $(\mathbf{5 0})$ in the chromatograms. The yield of trans-coniferyl alcohol and trans-synapyl alcohol decreased after the washing treatment but the yield of coniferaldehyde and synapaldehyde is unchanged. As an effect of steam explosion, the peak of trans-coniferyl alcohol disappeared, the yield of trans-synapyl alcohol and the two aldehydes compounds decreased as well. Apparently, the thermolabile $-\mathrm{CH}_{2}-\mathrm{OH}$ groups in gamma positions had been cleaved from the lignin monomeric units during the steam explosion treatment (Scheme 1) therefore the yield of coniferyl and synapyl alcohols and aldehydes is significantly reduced in the pyrolyzate of the steam exploded samples. This change of the lignin structure also explains the decreased yield of formaldehyde during the pyrolysis of the hemp sample (Table 3). The TG/MS results confirm these observations: the yield of formaldehyde is reduced in the pyrolyzate of treated samples due to the reduced gamma $-\mathrm{CH}_{2}-\mathrm{OH}$ groups in the steam exploded lignin. So the composition of lignin component obviously changed by the steam explosion. Similar structural changes of the lignin component have been observed in the non-hydrolyzed softwood residues from bioethanol production by Dizhbite et al. [55]. 


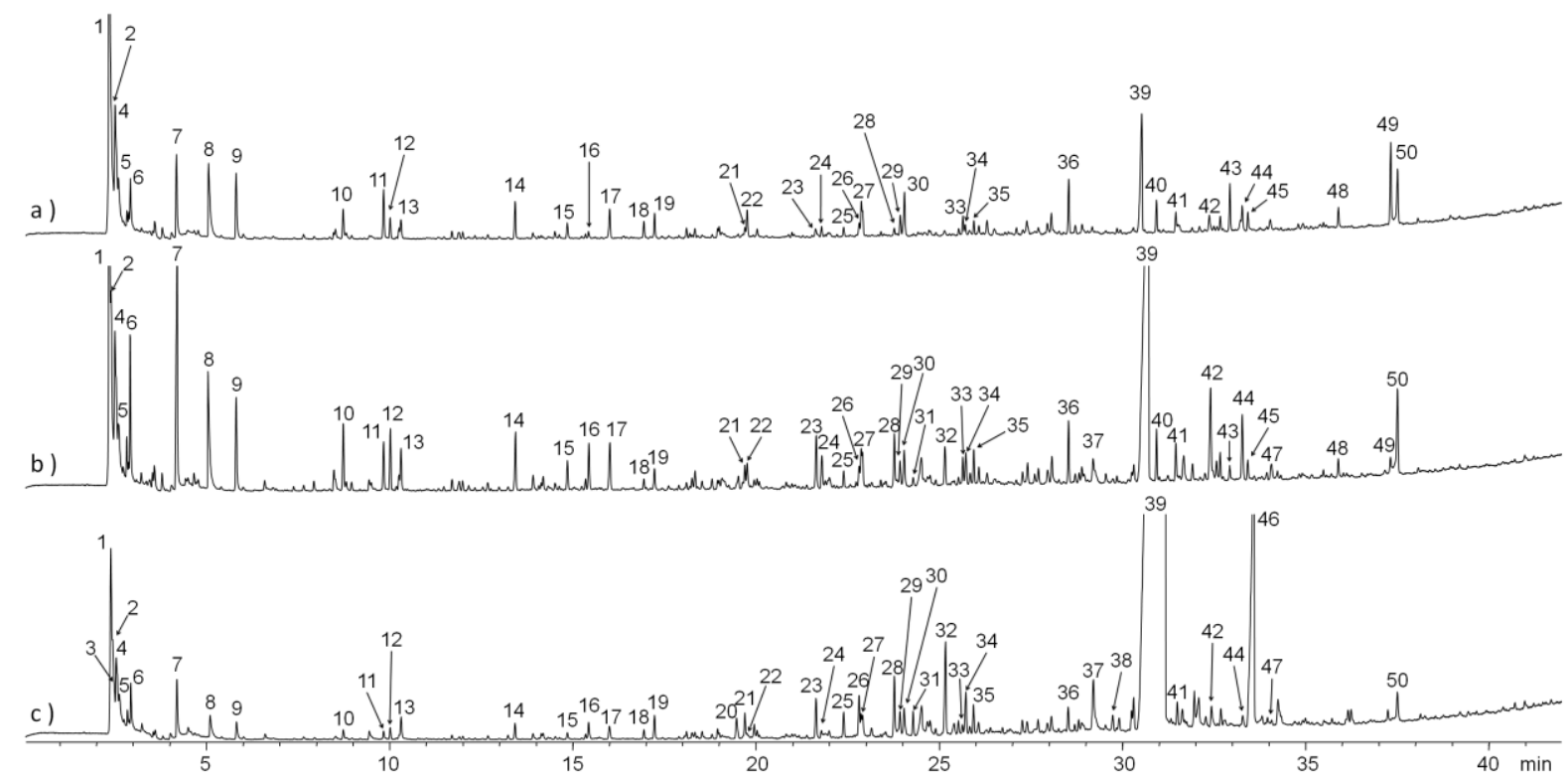

Fig. 5. Pyrograms of (a) native, (b) washed and (c) steam exploded hemp samples. Numbered peak identities are given in Table 3 .

\section{Table 3}

The main decomposition products released in the Py-GC/MS experiment of native, washed and steam exploded hemp samples. Peak numbers refer to the peaks in Fig. 5.

\begin{tabular}{|c|c|c|c|c|c|c|c|}
\hline 1 & 2.3 & Carbon dioxide & 44 & 44 & 19,43 & 10,69 & 2,47 \\
\hline 2 & 2.4 & Formaldehyde & 29,30 & 30 & 3,80 & 3,74 & 0,85 \\
\hline 3 & 2.5 & Sulfur dioxide & $64,48,32$ & 64 & & & 0,44 \\
\hline 5 & 2.7 & Methanol & $31,32,29$ & 32 & 3,84 & 2,55 & 0,69 \\
\hline 6 & 2.9 & Propanal-2-one & $43,29,72$ & 72 & 2,89 & 2,69 & 0,54 \\
\hline 7 & 4.2 & Hydroxy acetaldehyde & $31,29,32,60$ & 60 & 3,95 & 5,43 & 0,75 \\
\hline 8 & 5.1 & Acetic acid & $43,45,60$ & 60 & 5,07 & 3,48 & 0,43 \\
\hline 12 & 10.0 & 2-Hydroxybutanal-3-one & 43,102 & 102 & 0,85 & 1,21 & 0,11 \\
\hline 13 & 10.3 & Furfural & $96,95,39,67$ & 96 & 0,91 & 0,87 & 0,26 \\
\hline 14 & 13.4 & 1,2-Cyclopentandione & $98,55,42,69$ & 98 & 1,59 & 1,29 & 0,17 \\
\hline 15 & 14.9 & (5H)-Furan-2-one & $55,84,54$ & 84 & 0,79 & 0,66 & 0,08 \\
\hline 16 & 15.4 & 4-Hydroxy-5,6-dihydro-(2H)-pyran-2-one & $114,58,29$ & 114 & 0,37 & 1,05 & 0,20 \\
\hline 17 & 16.0 & 2-Hydroxy-3-methyl-2-cyclopenten-1-one & $112,69,55,83$ & 112 & 1,46 & 1,25 & 0,17 \\
\hline 18 & 16.9 & Phenol & $94,66,65,39$ & 94 & 0,69 & 0,22 & 0,09 \\
\hline 19 & 17.2 & Guaiacol & $109,124,81$ & 124 & 1,13 & 0,53 & 0,27 \\
\hline 20 & 19.5 & Carbohydrate & $98,66,53,144$ & 144 & & & 0,29 \\
\hline
\end{tabular}




\begin{tabular}{|c|c|c|c|c|c|c|c|}
\hline 21 & 19.7 & 4-Methylguaiacol & $138,123,95,77$ & 138 & 0,39 & 0,47 & 0,28 \\
\hline 22 & 19.8 & Anhydrosugar & $44,57,43$ & 132 & 1,25 & 0,64 & 0,08 \\
\hline 23 & 21.6 & 4-Ethylguaiacol & $137,152,122$ & 152 & 0,48 & 1,43 & 0,47 \\
\hline 24 & 21.8 & $\begin{array}{l}\text { 4-Hydroxy-3-methyl-(5H)-furanone or } \\
\text { 3-Methyl-2,4-furandione }\end{array}$ & $114,56,84,42$ & 114 & 0,51 & 0,88 & 0,10 \\
\hline 25 & 22.4 & 1,4:3,6-Dianhydro- $\alpha$-D-glucopyranose & $69,57,41,98,144$ & 144 & 0,49 & 0,36 & 0,30 \\
\hline 26 & 22.8 & 3-Methoxycatechol & $140,125,97$ & 140 & 0,60 & 0,45 & 0,44 \\
\hline 27 & 22.9 & 4-Vinylguaiacol & $150,135,107,77$ & 150 & 1,42 & 0,74 & 0,23 \\
\hline 28 & 23.8 & 5-Hydroxymethyl-2-furaldehyde & $97,126,41,69$ & 126 & 0,42 & 1,32 & 0,74 \\
\hline 29 & 23.9 & 1,2-Benzenediol & $110,64,81,92$ & 110 & 0,94 & 0,62 & 0,29 \\
\hline 30 & 24.1 & Syringol & $154,139,111,96$ & 154 & 2,32 & 1,07 & 0,39 \\
\hline 31 & 24.3 & Unknown & $43,69,57,73$ & & & 0,29 & 0,28 \\
\hline 32 & 25.2 & $\begin{array}{l}\text { 2-Hydroxymethyl-5-hydroxy-2,3-dihydro- } \\
\text { (4H)-pyran-4-one }\end{array}$ & $144,87,97$ & 144 & & 0,92 & 1,14 \\
\hline 33 & 25.6 & trans-Isoeugenol & $164,149,131,103$ & 164 & 0,79 & 0,60 & 0,13 \\
\hline 34 & 25.7 & 1,5-Anhydro- $\beta$-D-xylofuranose & $57,73,43$ & 132 & 0,49 & 0,80 & 0,56 \\
\hline 35 & 25.9 & 4-Methylsyringol & $168,153,125$ & 168 & 0,61 & 0,75 & 0,34 \\
\hline 36 & 28.5 & 4-Vinylsyringol & $180,165,137$ & 180 & 2,43 & 1,31 & 0,26 \\
\hline 37 & 29.2 & 1,6-Anhydro- $\alpha$-D-galactopyranose & $60,57,73$ & 162 & & 0,74 & 0,86 \\
\hline 38 & 29.7 & $\alpha$-Oxy-propioguaiacone & $151,123,108$ & 194 & & & 0,23 \\
\hline 39 & 30.5 & $\begin{array}{l}\text { 1,6-Anhydro- } \beta \text {-D-glucopyranose } \\
\text { (Levoglucosan) }\end{array}$ & $60,57,73$ & 162 & 7,95 & 29,08 & 75,02 \\
\hline 40 & 30.9 & trans-4-Propenylsyringol & $194,91,179$ & 194 & 1,48 & 1,10 & \\
\hline 41 & 31.5 & Syringaldehyde & $182,181,167,111$ & 182 & 1,00 & 0,85 & 0,28 \\
\hline 42 & 32.4 & Anhydrosugar & $45,69,73,41$ & & 1,03 & 2,72 & 0,42 \\
\hline 43 & 32.9 & trans-Coniferyl alcohol & $137,180,124,91$ & 180 & 2,11 & 0,35 & \\
\hline 44 & 33.3 & Coniferaldehyde & $178,135,147,107$ & 178 & 1,26 & 1,70 & 0,17 \\
\hline 45 & 33.4 & Syringyl acetone & $167,210,123$ & 210 & 0,91 & 0,50 & \\
\hline 46 & 33.6 & 1,6-Anhydro- $\beta$-D-glucofuranose & $73,69,44,43$ & 162 & & & 7,02 \\
\hline 47 & 34.1 & $\alpha$-Oxy-propiosyringone & $181,43,182$ & 224 & & 0,76 & 0,07 \\
\hline 48 & 35.9 & cis-Synapyl alcohol & $210,167,154,182$ & 210 & 0,93 & 0,56 & \\
\hline 49 & 37.3 & trans-Synapyl alcohol & $210,167,154,182$ & 210 & 4,08 & 0,53 & \\
\hline 50 & 37.5 & Synapaldehyde & $208,165,137,177$ & 208 & 3,39 & 2,81 & 0,44 \\
\hline
\end{tabular}

*area $\%$ of the identified peaks of native, washed and steam exploded sample

Table 4

Relative amount of 3-methoxycatechol and catechol in the pyrolyzates of the samples.

3-methoxycatechol $\%$ of total lignin area

Catechol \% of total lignin area

\begin{tabular}{lccccc}
\hline Samples & Willow & Hemp & Wheat straw & $\begin{array}{c}\text { Sweet sorghum } \\
\text { bagasse }\end{array}$ & Spruce \\
\hline Native & 2.5 & 1.9 & 1.2 & 1.6 & 4.7 \\
Washed & 4.9 & 2.0 & 1.5 & 2.4 & 5.4 \\
Steam exploded & 6.3 & 7.8 & 1.7 & 3.4 & 15.0 \\
\hline
\end{tabular}




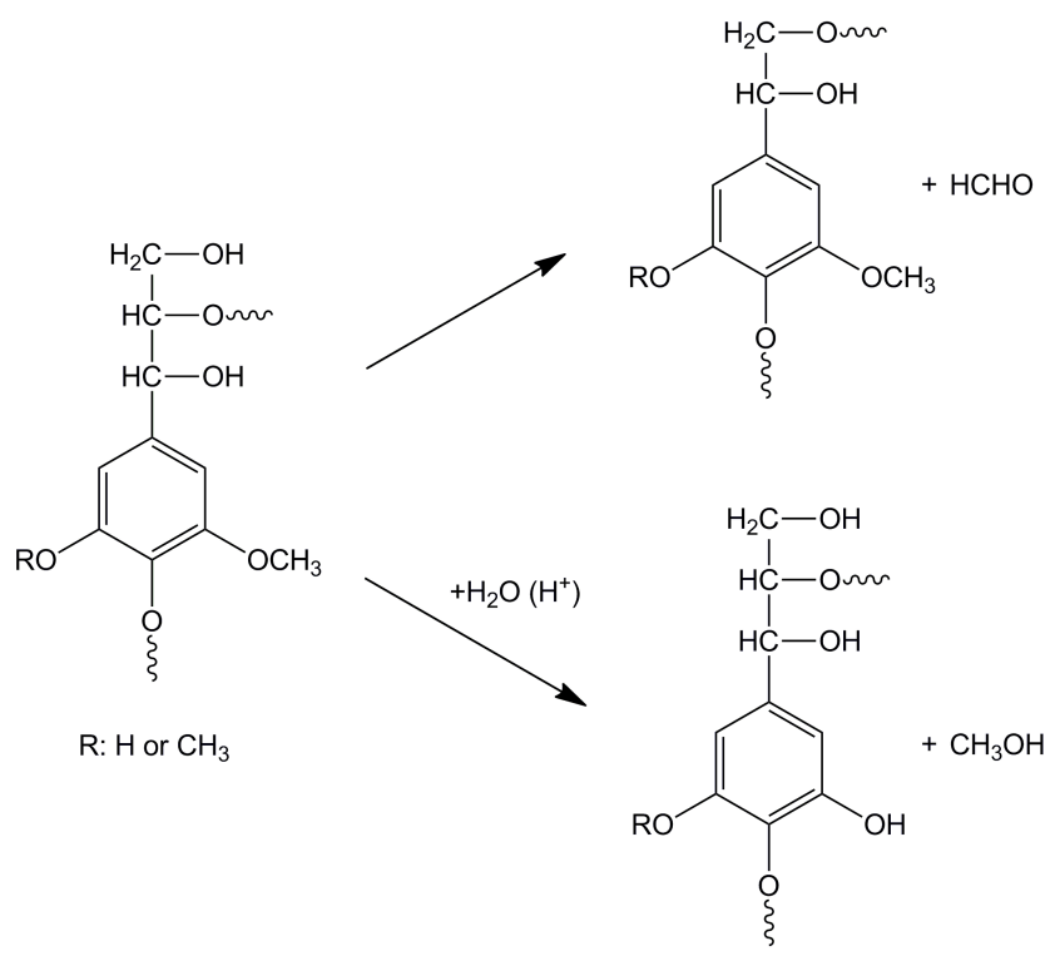

Scheme 1. Modification of the lignin molecules during the steam explosion.

\section{PCA calculations}

Principal component analysis has been applied to find correlations in the changes of the functional groups of the lignin molecules incurred by the steam explosion. In the PCA calculation, the relative amounts of lignin products containing alkyl, alkenyl, oxo, aliphatic hydroxyl, phenolic - $\mathrm{OH}$ groups and lignin monomers without aliphatic functional groups have been used in comparison with the summed intensities of lignin products. The results have been obtained using all peaks of lignin monomers in the pyrolysis chromatograms of native and steam exploded samples. In the PCA the first principal component (Factor 1) describes $45.5 \%$ and the second principal component (Factor 2) explains $27.9 \%$ of the total variance. In the score plot (Fig. 6a) it can be seen that the native samples differ markedly from the steam exploded samples, excluding the sweet sorghum bagasse samples. The wheat straw and the sweet sorghum bagasse were pretreated using the mildest steam explosion parameters, but the applied impregnation material was different (Table 1). $\mathrm{H}_{2} \mathrm{SO}_{4}$ was applied during the pretreatment of the wheat straw, while $\mathrm{SO}_{2}$ was used in case of sweet sorghum bagasse. Apparently, the milder conditions and catalyst caused no changes in the structure of functional groups of lignin molecules of the sweet sorghum bagasse. It should be noted that sweet sorghum bagasse is a residue obtained after sugar juice extraction from the sweet sorghum stalk and this treatment might have caused already some changes in its structure. As the score plot indicates in Fig. 6a, the difference between the native and steam exploded samples is characterized mainly by Factor 1. The loading plot (Fig. 6b) suggests that the pyrolyzates of the native samples contain higher amount of aliphatic hydroxyl and $\mathrm{C}_{3}$-alkenyl groups, whereas the pyrolyzates of the steam exploded samples have shorter aliphatic chains or no aliphatic side groups and more phenolic hydroxyl groups. This is in agreement with the 
previously described conclusions: The steam explosion leads to the shortening of the alkyl side chains and the scission of methyl groups from the methoxyl side groups. The native and steam exploded woody samples differ to a great extent from the herbaceous samples as described mainly by Factor 2. Spruce and willow samples release more oxogroup-containing lignin monomers than the herbaceous samples.
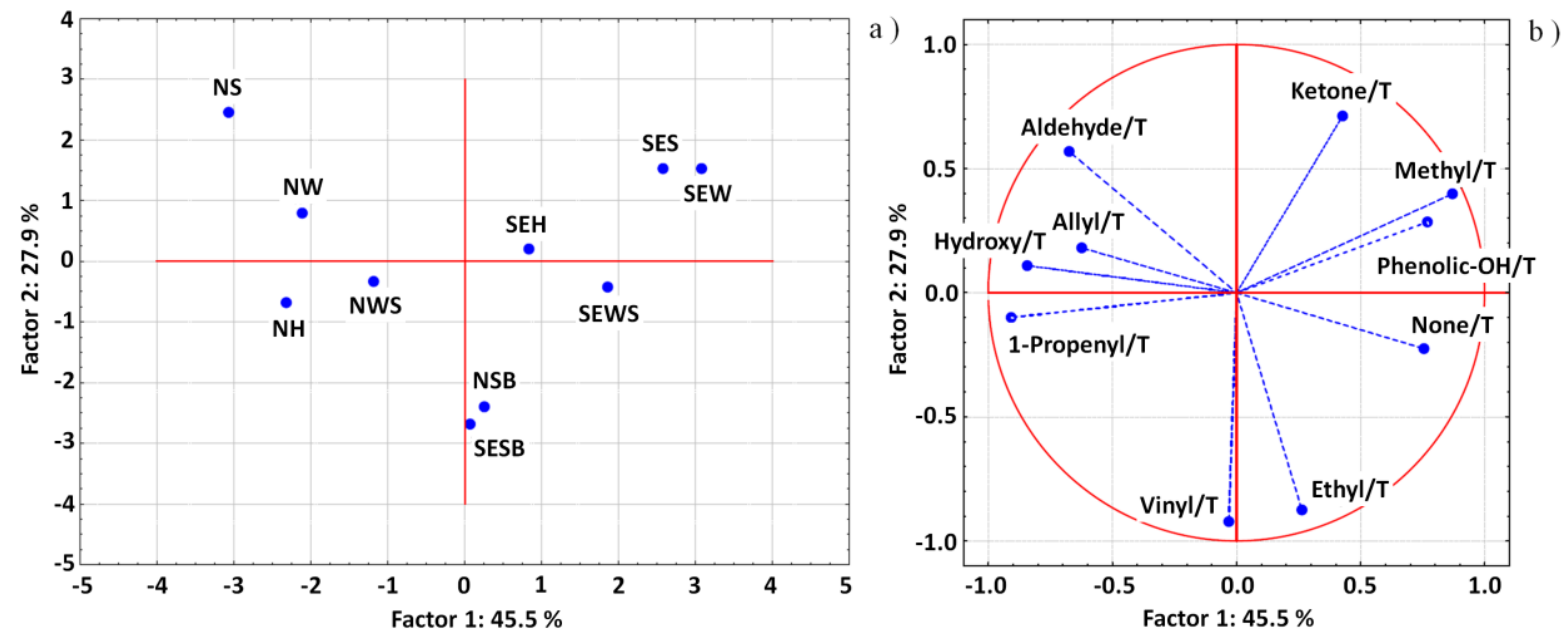

Fig. 6. Results of principal component analysis based on the functional group composition of lignin pyrolysis products: (a) score and (b) loading plot. N, native; SE, steam exploded; S, spruce; W, willow; H, hemp; WS, wheat straw; SB, sweet sorghum bagasse.

\section{Conclusions}

Native, washed and steam exploded woody and herbaceous plant samples were analyzed by thermal analysis methods (TG/MS and Py-GC/MS) with the goals of determining the structural changes of main components; comparing the effects of steam explosion in the woody and herbaceous biomass samples and revealing the influence of the different alkali ion content on the thermal decomposition.

The TG/MS and Py-GC/MS results show that the hemicellulose content was decreased, while the relative amounts of cellulose and lignin were increased during steam explosion. The severity of steam explosion was higher in wood samples than in the herbaceous plant samples, which caused greater structural changes. The reduced thermal stability of steam exploded wood samples indicates the modification of cellulose structure (e.g., crystallinity, degree of polymerization). The altered distribution of the pyrolysis products of lignin shows that the structure of lignin molecules was modified by the steam explosion. Demethylation of the methoxyl groups is indicated by the increased yield of cathecol and 3-methoxybenzene-1,2diol. Shortening of alkyl side groups is confirmed by the reduction of the yield of coniferyl and synapyl alcohol and aldehyde. Statistical correlations have been found between the functional group composition of lignin pyrolysis products in native and steam exploded samples using Principal Component Analysis. There is no significant change in the lignin structure of sweet sorghum bagasse because the steam explosion was less severe and the impregnation material was $\mathrm{SO}_{2}$ instead of $\mathrm{H}_{2} \mathrm{SO}_{4}$. Furthermore sweet sorghum bagasse is the 
only sample that has been treated before the steam explosion, since it is a residue after the sugar extraction.

The alkali ion content of the samples was diminished by washing and steam explosion resulting in the shift of thermal decomposition of cellulose component to higher temperature in herbaceous plant samples. Depolymerization is the preferred way of decomposition in treated samples against the fragmentation and char formation in native samples of high alkali ion content.

\section{Acknowledgement}

This research was supported by the Hungarian National Research Fund (OTKA K81959, K72710 and PD75740). The authors are grateful to Prof. Guido Zacchi (Lund University) for the samples, to Dr. Gábor Várhegyi for the TG/MS analysis programs and to Dr. János Bozi for the help in pyrolysis experiments.

\section{References}

1. C.C.O. Scacchi, S. González-García, S. Caserini, L. Rigamonti, Greenhouse gases emission and energy use of wheat grain-based bioethanol fuel blends, Sci. Total Environ. 408 (2010) 5010-5018.

2. S. Brethauer, C.E. Wyman, Rewiev: Continuous hydrolysis and fermentation for cellulosic ethanol production, Bioresource Technol. 101 (2010) 4862-4874.

3. Zs. Barta, J.M. Oliva, I. Ballesteros, D. Dienes, M. Ballesteros, K. Réczey, Refining hemp hurds into fermentable sugars or ethanol, Chem. Biochem. Eng. Q. 24(3) (2010) 331-339.

4. B. Sipos, E. Kreuger, S.E. Svensson, K. Réczey, L. Björnsson, G. Zacchi, Steam pretreatment of dry and ensiled industrial hemp for ethanol production, Biomass Bioenerg. 34 (2010) 1721-1731.

5. D. Salvachúa, A. Prieto, M. López-Abelairas, T. Lu-Chau, Á.T. Martínez, M.J. Martínez, Fungal pretreatment: An alternative in second-generation ethanol from wheat straw, Bioresource Technol. 102 (2011) 7500-7506.

6. B.D. Solomon, J.R. Barnes, K.E. Halvorsen, Grain and cellulosic ethanol: History, economics, and energy policy, Biomass Bioenerg. 31 (2007) 416-425.

7. E. Sjöström, Wood chemistry: Fundamentals and applications, Academic Press, New York, 1981

8. J.M. Igartuburu, E. Pando, F. Rodríguez-Luis, A. Gil-Serrano, Structure of hemicellulose A fraction in dietary fiber from the seed of grape variety Palomino (Vitis vinifera cv. Palomino), J. Nat. Prod. 61 (1998) 876-880. 
9. E. Jakab, O. Faix, F. Till, T. Székely, Thermogravimetry/mass spectrometry study of six lignins within the scope of an international round robin test, J. Anal. Appl. Pyrol. 35 (1995) 167-179.

10. J. Li, G. Gellerstedt, K. Toven, Steam explosion lignins; their extraction, structure and potential as feedstock for biodiesel and chemicals, Bioresource Technol. 100 (2009) 2556-2561.

11. J.C. del Río, A. Gutierrez, I.M. Rodriguez, D. Ibarra, Á.T. Martínez, Composition of non-woody plant lignins and cinnamic acids by Py-GC/MS, Py/TMAH and FTIR, J. Anal. Appl. Pyrol. 79 (2007) 39-46.

12. O. Faix, D. Meier, I. Grobe, Studies on isolated lignins and lignins in woody materials by pyrolysis-gas chromatography-mass spectrometry and off-line pyrolysis-gas chromatography with flame ionization detection, J. Anal. Appl. Pyrol. 11 (1987) 403416.

13. S.H. da Cruz, B.S. Dien, N.N. Nichols, B.C. Saha, M.A. Cotta, Hydrothermal pretreatment of sugarcane bagasse using response surface methodology improves digestibility and ethanol production by SSF, J. Ind. Microbiol. Biotechnol. 39 (2012) 439-447.

14. E. Kreuger, B. Sipos, G. Zacchi, S.E. Svensson, L. Björnsson, Bioconversion of industrial hemp to ethanol and methane: The benefits of steam pretreatment and coproduction, Bioresource Technol. 102 (2011) 3457-3465.

15. F. Schuett, J. Puls, B. Saake, Optimization of steam pretreatment conditions for enzymatic hydrolysis of poplar wood, Holzforschung 65(4) (2011) 453-459.

16. S.G. Allen, L.C. Kam, A.J. Zemann, M.J. Antal, Fractionation of sugar cane with hot, compressed, liquid water, Ind. Eng. Chem. Res. 35(8) (1996) 2709-2715.

17. A.S. da Silva, H. Inoue, T. Endo, S. Yano, E.P.S. Bon, Milling pretreatment of sugarcane bagasse and straw for enzymatic hydrolysis and ethanol fermentation, Bioresource Technol. 101 (2010) 7402-7409.

18. Y. López, B. Gullón, J. Puls, J.C. Parajó, C. Martín, Dilute acid pretreatment of starchcontaining rice hulls for ethanol production, Holzforschung 65 (2011) 467-473.

19. Z. Sebestyén, Z. May, K. Réczey, E. Jakab, The effect of alkaline pretreatment on the thermal decomposition of hemp, J. Therm. Anal. Calorim. 105 (2011) 1061-1069.

20. D. Haverty, K. Dussan, A.V. Piterina, J.J. Laehy, M.H.B. Hayes, Autothermal, singlestage, performic acid pretreatment of Miscanthus $x$ giganteus for the rapid fractionation of its biomass components into a lignin/hemicellulose-rich liquor and a cellulase-digestible pulp, Bioresource Technol. 109 (2012) 173-177.

21. J. Yu, J. Zhang, J. He, Z. Liu, Z. Yu, Combinations of mild physical or chemical pretreatment with biological pretreatment for enzymatic hydrolysis of rice hull, Bioresource Technol. 100 (2009) 903-908. 
22. R. Datar, J. Huang, P.C. Maness, A. Mohagheghi, S. Czernik, E. Chornet, Hydrogen production from the fermentation of corn stover biomass pretreated with a steamexplosion process, Int. J. Hydrogen Energ. 32 (2007) 932-939.

23. J. Li, G. Henriksson, G. Gellerstedt, Lignin depolymerization/repolymerization and its critical role for delignification of aspen wood by steam explosion, Bioresource Technol. 98 (2007) 3061-3068.

24. C. Asada, C. Sasaki, Y. Uto, J. Sakafuji, Y. Nakamura, Effect of steam explosion pretreatment with ultra-high temperature and pressure on effective utilization of softwood biomass, Biochem. Eng. J. 60 (2012) 25-29.

25. M.J. Negro, P. Manzanares, J.M. Oliva, I. Ballesteros, M. Ballesteros, Changes in various physical/chemical parameters of Pinus pinaster wood after steam explosion pretreatment, Biomass Bioenerg. 25 (2003) 301-308.

26. G. Han, J. Deng, S. Zhang, P. Bicho, Q. Wu, Effect of steam explosion treatment on characteristics of wheat straw, Ind. Crop. Prod. 31 (2010) 28-33.

27. B. Sipos, M. Szilágyi, Z. Sebestyén, R. Perazzini, D. Dienes, E. Jakab, C. Crestini, K. Réczey, Mechanism of the positive effect of poly(ethylene glycol) addition in enzymatic hydrolysis of steam pretreated lignocelluloses, C. R. Biol. 334 (2011) 812823.

28. A. Emmel, A.L. Mathias, F. Wypych, L.P. Ramos, Fraction of Eucalyptus grandis chips by dilute acid-catalysed steam explosion, Bioresource Technol. 86 (2003) 105115.

29. C. Carrasco, H.M. Baudel, J. Sendelius, T. Modig, C. Roslander, M. Galbe, B. HahnHägerdal, G. Zacchi, G. Lidén, $\mathrm{SO}_{2}$-catalyzed steam pretreatment and fermentation of enzymatically hydrolyzed sugarcane bagasse, Enzym. Microb. Tech. 46 (2010) 64-73.

30. C. Torri, A. Adamiano, D. Fabbri, C. Lindfors, A. Monti, A. Oasmaa, Comparative analysis of pyrolysate from herbaceous and woody energy crops by Py-GC with atomic emission and mass spectrometric detection, J. Anal. Appl. Pyrol. 88 (2010) 175-180.

31. C. Schwarzinger, M. List, Identification of marker compounds in pyrolysis-GC/MS of various acetylated wood types J. Anal. Appl. Pyrol. 87 (2010) 144-153.

32. P. Sassner, M. Galbe, G. Zacchi, Steam pretreatment of Salix with and without $\mathrm{SO}_{2}$ impregnation for production of bioethanol, Appl. Biochem. Biotechnol. 121-124 (2005) 1101-1117.

33. K. Stenberg, C. Tengborg, M. Galbe, G. Zacchi, Optimisation of steam pretreatment of $\mathrm{SO}_{2}$ impregnated mixed softwoods for ethanol production, J. Chem. Technol.

Biotechnol. 71 (1998) 299-308. 
34. M. Linde, E.L. Jakobsson, M. Galbe, G. Zacchi, Steam pretreatment of dilute $\mathrm{H}_{2} \mathrm{SO}_{4}{ }^{-}$ impregnated wheat straw and SSF with low yeast and enzyme loadings for bioethanol production, Biomass Bioenerg. 32 (2008) 326-332.

35. B. Sipos, J. Réczey, Zs. Somorai, Zs. Kádár, D. Dienes, K. Réczey, Sweet sorghum as feedstock for ethanol production: enzymatic hydrolysis of steam-pretreated bagasse, Appl. Biochem. Biotechnol. 153 (2009) 151-162.

36. R.P. Overend, E. Chornet, Fractionation of lignocellulosics by steam aqueous pretreatment, Philos. Trans. R. Soc. Lond. A, 321 (1987) 523-536.

37. W.F. DeGroot, F. Shafizadeh, The influence of exchangeable cations on the carbonization of biomass, J. Anal. Appl. Pyrol. 6(3) (1984) 217-232.

38. Tanczos I, Gy. Pokol, J. Borsa, T. Tóth, H. Schmidt, The effect of tetramethylammonium hydroxide in comparison with the effect of sodium hydroxide on the slow pyrolysis of cellulose, J. Anal. Appl. Pyrol. 68-69 (2003) 173-185.

39. H. Kawamoto, D. Yamamoto, S. Saka, Influence of neutral inorganic chlorides on primary and secondary char formation from cellulose, J. Wood Sci. (2008) 54:242246.

40. D.J. Nowakowski, J.M. Jones, Uncatalysed and potassium-catalysed pyrolysis of the cell-wall constituents of biomass and their model compounds, J. Anal. Appl. Pyrol. 83 (2008) 12-25.

41. Zs.A. Mayer, A. Apfelbacher, A. Hornung, A comparative study on the pyrolysis of metal- and ash-enriched wood and the combustion properties of the gained char, $\mathrm{J}$. Anal. Appl. Pyrol. 96 (2012) 196-202.

42. E. Jakab, O. Faix, F. Till, Thermal decomposition of milled wood lignins studied by thermogravimetry/mass spectrometry, J. Anal. Appl. Pyrol. 40-41 (1997) 171-186.

43. E. Jakab, O. Faix, F. Till, T. Székely, The Effect of Cations on the Thermal Decomposition of Lignins, J. Anal. Appl. Pyrol. 25 (1993) 185-194.

44. P. Szabó, G. Várhegyi, F. Till, O. Faix, Thermogravimetric/mass spectrometric characterization of two energy crops, Arundo donax and Miscanthus sinensis, J. Anal. Appl. Pyrol. 36 (1996) 179-190.1

45. G. Várhegyi, M.G. Gronli, C. Di Blasi, Effects of sample origin, extraction, and hotwater washing on the devolatilization kinetics of chestnut wood, Ind. Eng. Chem. Res. 43(10) (2004) 2356-2367.

46. F. Shafizadeh, Pyrolysis and combustion of cellulosic materials, Adv. Carbohyd. Chem. Bi. 23 (1968) 419-474. 
47. E. Mészáros, E. Jakab, G. Várhegyi, P. Szepesváry, B. Marosvölgyi, Comparative study of the thermal behavior of wood and bark of young shoots obtained from an energy plantation, J. Anal. Appl. Pyrol. 72 (2004) 317-328.

48. G. Várhegyi, M.J. Antal, T. Székely, F. Till, E.Jakab, Simultaneous thermogravimetric-mass spectrometric studies of the thermal decomposition of biopolymers. 1. Avicel cellulose in the presence and absence of catalysts, Energ. Fuel 2 (1988) 267-272.

49. O. Faix, D. Meier, I. Fortmann, Thermal degradation products of wood - Gas chromatographic separation and mass spectrometric characterization on monomeric lignin derived products, Holz Roh Werkst. 48 (1990) 281-285.

50. O. Faix, D. Meier, I. Fortmann, Thermal degradation products of wood - A collection of electron-impact (EI) mass spectra of monomeric lignin derived products, Holz Roh Werkst. 48 (1990) 351-354.

51. O. Faix, I. Fortmann, J. Bremer, D. Meier, Thermal degradation products of wood Gas chromatographic separation and mass spectrometric characterization on polysaccharide derived products, Holz Roh Werkst. 49 (1991) 213-219.

52. O. Faix, I. Fortmann, J. Bremer, D. Meier, Thermal degradation products of wood - A collection of electron-impact (EI) mass spectra of polysaccharide derived products, Holz Roh Werkst. 49 (1991) 299-304.

53. J. Kelly, R. Helleur, Quantitative analysis of the major saccharides in sulfite-treated wood pupls by pyrolysis-gas chromatography: the effect of metal ions, J. Anal. Appl. Pyrol. 23 (1992) 153-163.

54. D.R. Budgell, E.R. Hayes, R.J. Helleur, Direct identification of pentoses and hexoses by pyrolysis/capillary gas chromatography, Anal. Chim. Acta 192 (1987) 243-253.

55. T. Dizhbite, G. Telysheva, G. Dobele, A. Arshanitsa, O. Bikovens, A. Andersone, V. Kampars, Py-GC/MS for characterization of non-hydrolyzed residues from bioethanol production from softwood, J. Anal. Appl. Pyrol. 90 (2011) 126-132. 